\title{
On a Silk Military Colour of Russia during Peter I
}

\author{
SU Miao ${ }^{1,2}$, ZHAO Feng ${ }^{1,3} \&$ YANG Rulin ${ }^{3}$ \\ ${ }^{1}$ Fashion Art Design Institute, Donghua University, Shanghai, China \\ ${ }^{2}$ Institute of Silk, College of Materials and Textiles, Zhejiang Sci-Tech University, Hangzhou, China \\ ${ }^{3}$ China National Silk Museum, Hangzhou, China \\ Correspondence: SU Miao, Institute of Silk, College of Materials and Textiles, Zhejiang Sci-Tech University, \\ NO.928, the 2nd Street, Xiasha Higher Education District, Hangzhou,310018,China. Tel: 86-133-3600-7606. \\ E-mail: sumiao2008@qq.com
}

Received: June 1, 2017

doi:10.5539/ass.v13n8p176
Accepted: June 21, $2017 \quad$ Online Published: July 25, 2017

URL: https://doi.org/10.5539/ass.v13n8p176

\begin{abstract}
This paper studies a silk military colour during the reign of Tsar Peter I in the collection of the Swedish Army Museum, discussing the colour from the perspectives of several aspects including the background, the shape and form, the decorative theme, the fabric variety and the silk pattern. Analysis and researches on the fabric weave and pattern are the main focuses of this paper and the recovery of the fabric's pattern is also included. And on the basis of physical research, combining with the comprehensive analysis of the wars and the style of the colour, the authors identify that these silk fabrics used for the Russian military colour are Chinese satin damask of late Ming and early Qing dynasties.
\end{abstract}

Keywords: Military Colour, Tsar Peter I, Fabric Weave, Silk Pattern, Ming and Qing Dynasties

\section{Introduction}

There are over 300 military colours collected in the Swedish Army Museum, which were captured by Swedish Army during the Great Northern War in the early $18^{\text {th }}$ century. Most of them were the trophies seized in several battles against Russia from the year of 1700 to 1707. There is a Russian banner, No. ST21:27 ( as shown in Fig.1), that was a trophy from the war in the early $18^{\text {th }}$ century. It's rectangular with a size of $268 \mathrm{~cm} * 253 \mathrm{~cm}$. Based on researches, this colour proves to be sewed by several pieces of Chinese silk with patterns on which there are religious painting. This paper will conduct researches on the banner from the perspective of its shape, form, decoration process, fabric and pattern. Besides, during the discussion, we'll also have a recovery description of the silk patterns of its main fabric.

\section{The Background of the Military Colour Relics}

In the late $17^{\text {th }}$ century and the early $18^{\text {th }}$ century, Russia was still a backward country entrenched in the northeast of the Baltic Sea. In 1698, when Peter I (Peter the Great ) returned to Russia after a profound investigation in west Europe, he started a series of military, political and social reform in Russia. As for the outside world, the Russia Army was involved in the war with Turkey by the south, and with Sweden by the north. Aligned with Denmark and Saxony, Russia declared war against Sweden, the European military power at that time. Later Poland joined the war, then the Great Northern War started, finally the Russia was defeated in the Battle of Narve in November, 1700. From then on, the Swedish Emperor, Charlie XII, diverted his attention to other enemies. At the same time, Peter I rebuilt his army. Later, Sweden and Russia were engaged in battles again until Sweden lost its power to the Battle of Poltava in 1709.

This Russian colour collected in the Swedish Army Museum, No. ST21:27, is registered as the Russian banner in the early $18^{\text {th }}$ century, which is a trophy captured in the former battles during the Great Northern War. It's recorded in profiles that this banner might be either a trophy of the Narva Battle in November, 1700, or a trophy of the Saladen Battle in March, 1703. The captured colour, as a symbol of national honor, was taken back to Sweden as soon as the war ended, and then was displayed and collected in Stockholm. More than 300 years from then on, the banner, along with other trophies were fairly preserved regardless of being relocated for several times. 


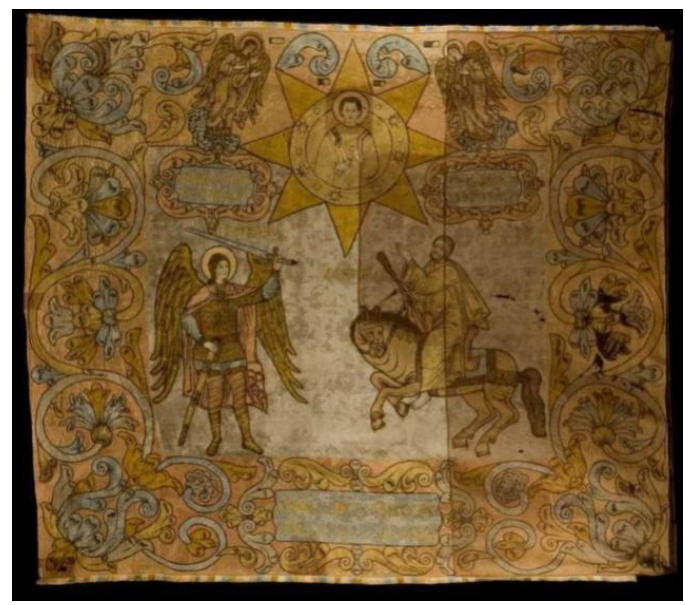

Figure 1. A Military Banner of Russia ST 21:27

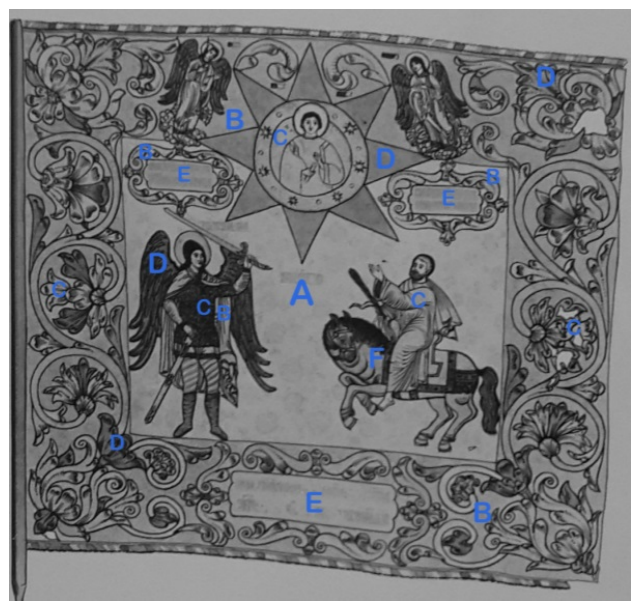

Figure 2. Diagram of Using the Fabrics

\section{The Shape, Form and Decoration Theme of the Military Colour}

This Russian banner has a rectangular shape, with a creamy white rectangular base cloth, $170 \mathrm{~cm} * 134 \mathrm{~cm}$, in the center and embraced by a light reddish brown base cloth with a width of about $50 \mathrm{~cm}$. There are mainly three kinds of European military colours form $16^{\text {th }}$ to $18^{\text {th }}$ century--infantry colour, cavalry standard and dragoon guidon. The first type is rectangular with a size of about $1.5 \mathrm{~m} * 3 \mathrm{~m}$, carried by infantry in battles. The second type is either square or rectangular with a size of $55 \mathrm{~cm} * 55 \mathrm{~cm}$, carried by cavalry in battles. The last type often shapes like a swallow tail and sometimes is triangular with a length of about $1 \mathrm{~m}$. The soldiers who hold this banner often march ahead on the horse and fight on the ground. According to its style and size, the colour is supposed to belong to Infantry.

The infantry colour is jointly seamed with pieces of fabric, on which there are paintings of religious themes. According to different colors and design, the military colour with specific theme pattern consists of various fabrics. This similar patchwork technique has been widely used in European flags from 16th to 18th centuries, such as the flags of Denmark, Saxony, Bohemia and the Holy Roman Empire. To make such a flag, first of all, we need to choose the fabric with the corresponding color in line with the design of the decorative patterns, and then cut the fabric according to the shape of the target patterns. Take the production of NO.ST21: 27 for example, in accordance with the drawing, we need to cut the golden fabric into eight triangles as the rays of light, then cut the brown fabric into the shape of wings as the Archangel St. Micheal's wings, and cut the light blue fabric into several rectangles with different sizes as part of the word plates......After that, we seam all the fabrics together as expected to form a whole piece of colour, which can guarantee the same appearance of the two sides. And then the same painting details will be drawn on both sides according to the patterns, such as the face of the character, the feather textures, veins of flowers and branches and so on. The patchwork and painting, two art techniques, together constitute a typical scene of the Orthodox theme with the same content on both sides of colour. From Figure 1, the upper part of the paint is God holding the Bible with lights around him, and slogan plates are decorated on his both sides. On the left side of the picture stands the Archangel St. Michael holding the sword, and on the right is the prophet Balaam ridding the donkey. Their heads are slightly up, facing toward God, who's standing in the central part of the picture. The edges are decorated with flowers and vines, and in the middle of the lower edge is a light blue rectangle with a slogan plate.

Military colour with religious theme that directly portrays the image of religious figures is of typical use for the Russian army before the military reform of Peter I. A series of military reforms were carried out by Peter I after he was back from Western Europe in 1698, including a re-adjustment of the style of the military's banners and the banner's decoration at all levels. And he ordered the colours be reproduced in accordance with the new regulations. Since then, such flags with early religious theme were almost no longer produced, but the army could continue to use them, so it's assumed that this colour should be produced before 1698. What was recorded in Swedish Army Museum archives was that this colour was made in around 1690, which is also consistent with our assumption.

\section{The Distribution and Variety of Fabrics Used in the Colour}

After identification, there were at least six different types of silk fabrics in the banner. According to the pattern design, the six main fabrics were used in the corresponding location, and some were repeatedly used in many areas. The distribution of the main fabric is illustrated in Fig 2. 
Fabric A, which is now creamy white, is the base cloth of the central part, consisting of three pieces of patchwork;

Fabric B, which is now light reddish brown, is the edges base fabric and is used in the cloak of the Archangel St. Michael and the leaves around the plates on both sides of God;

Fabric C, whose original color was light yellow but now khaki, is used in the circular halo around God, the Prophet Balaam's clothes, Archangel Saint Micheal's dress and part of the edge of the leaf ornaments;

Fabric D, which is now golden brown, is used as the triangle rays of light radiated from the circular halo, Archangel St. Micheal's wings and some edges of the leaf ornaments;

Fabric E, which is light blue, is applied in three decorative plate parts, as well as part of the edges of the curved vines.

Fabric F, which is now khaki, is used in the donkey rode by the Prophet Balaam.

It's analyzed that these six main fabrics are all weaved by cultivated silk. Variety is single layer silk with satin weave on both sides including silk damask with the same-colored warp and weft and single layer of satin fabric with different-colored warp and weft. These two fabrics are made of positive and negative satin, which can make the front and back silk pattern the same characteristics, and is consistent with the ideas to keep the appearance of the flag on both sides as the same.

Fabric A, B, C, D, F are all satin fabric with imperceptible patterns whose weaving structures are five-end satin. Based on the unearthed cultural relics, the earliest five-end satin was found in Qian Yu's Tomb in Wuxi, Jiangsu Province, which was built with some burial objects of the Southern Song Dynasty in the seventh year of the Yuan Dynasty under the reign of Emperor Yanyou. After that, some other five-end satin were also unearthed from Li Yu'an's tomb in Zou County, Shandong Province, Cao's tomb in Wu County, Jiangsu Province, and Ming Yuzhen's tombs in Chongqing. The literature from Song and Yuan Dynasty to the beginning of the Ming Dynasty recorded satin as "Zhu-si", and the five-end satin as "An-hua Zhu-si" (which means there are unconspicuous patterns in the silk). Since then, in the Ming and Qing dynasty the satin was called the "silk damask". The five-end satin with the same-colored warp and weft is a typical satin fabric from the Ming Dynasty to the early stage of Qing Dynasty. The Russian colour used the same-colored warps and wefts in the silk damask, only with some slightly different shades. Warps either with some $\mathrm{Z}$ twist or without visible twists, have thinner yarns. And wefts have no twists, and looks looser and thicker. The dense of its warps ranges from 110 to $120 / \mathrm{cm}$, and that of its wefts is sparse, which mostly is at the range from 32 to $40 / \mathrm{cm}$ and some is $52 / \mathrm{cm}$. Fabric C, whose weave micrograph is shown in Fig 4, uses warps satin for the background and wefts the flowers, with a 115/cm dense of warp and $40 / \mathrm{cm}$ of weft and with Z-twist and no visible twists respectively. These silk damasks are more compact and tight, and feel crisp. Among the unearthed cultural relics of Ming Dynasty, we can see a lot of similar damasks like peony crane patterned scarf and clouds pattern damask robe unearthed in the tomb in Fengjiquan, Yanchi and so on. Most satin silks in the Ming Dynasty were five-end satin, and not until the Qing Dynasty did the seven-end and eight-end satin begin to appear. In the early Qing Dynasty, the poet, Qu Dajun wrote in $Z h u$ Zhi Ci that "five-end and eight-end satin in Guangdong are very good, which bring lots of fortune to the Thirteen-Trades Monopoly", which proves that in the early Qing Dynasty, five-end and eight-end satin with or without flowers were both produced and they sold well. Combined with the production elements of the flag and the time of war, and from the view of species, the fabric of silk damask of this military banner should be produced from the late Ming Dynasty to the early Qing Dynasty.

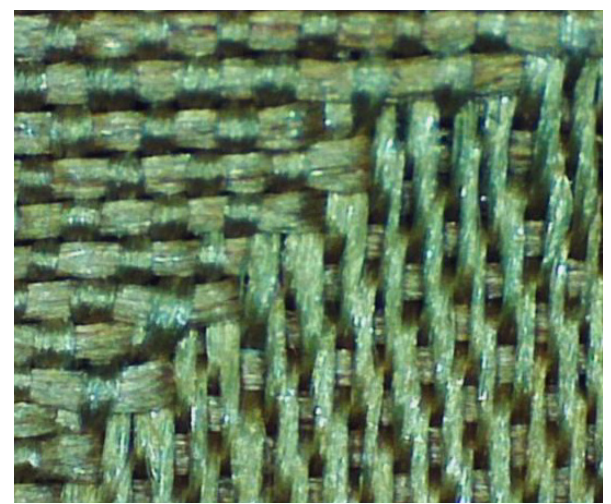

Figure 3. Weave of five-end satin damask

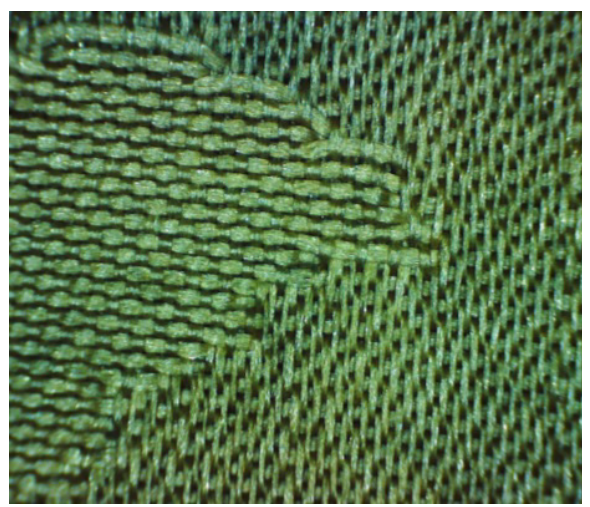

Figure 4. Weave of the fabric $\mathrm{C}$ 
Fabric $\mathrm{E}$ is single-layered satin with different-colored warp and weft, whose weave micrograph is shown in Fig 5 . Its weave structure is also five-end satin, using $115 / \mathrm{cm}$ dense of warp and $40 / \mathrm{cm}$ of weft and with Z-twist and no visible twists respectively. These parameters are consistent with fabrics A, B, C, D, F, but its warp is beige, weft blue, and the finished product is light blue. This kind of satin with different-colored warp and weft presents formation of different-colored background and pattern. Satin fabric with different-colored warp and weft can be named Shan Satin when there is great contrast between the colors of warp and weft, which is extremely popular in the Ming and Qing Dynasties. We can find many silk evidences in the collection of Beijing Art Museum, which is used for sutra cover. Usually, the warps of Shan satin have twist and the thread is thinner, while the wefts are fluffy thicker without twists. So the joints of warp and weft cover a smaller area that form a good flashing effect. In Qing Dynasty, the common colors of Shan satin are red changing into green, into pale blue, and into stone green, or stone green changing into bluish white, or blue changing into purple. From the perspective of color, Fabric E changes from stone green into bluish white, so it should be called Shan satin.

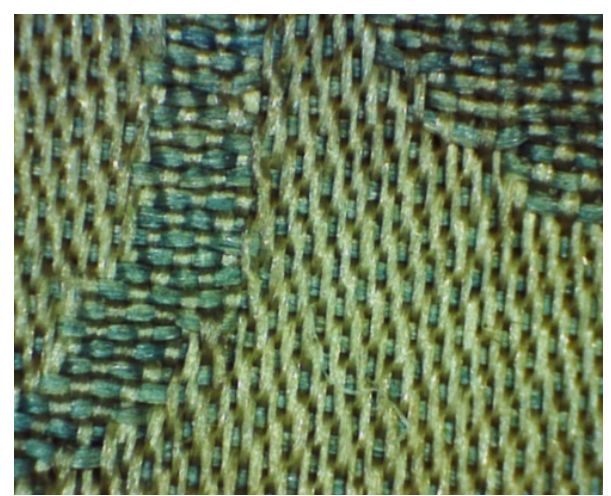

Figure 5. Weave of the fabric E

Silk damask and satin with different-colored warp and weft will go through the procedure of refined dyeing before weaving their warps and wefts. Wu Zimu, a man from Qiantang (now Hangzhou, Zhejiang Province) in Southern Song Dynasty once wrote in the Meng Liang Lu that silk damask was made of dyed silk, which also confirmed us that two-side satin fabric is dyed before weaved. By observing the technical staffs in Chinese Silk Museum making the fiber slices of the silk sample of military flags which are the same batch of the banner studied, we can basically be assured that the reality is consistent with the recorded data that the fabric with patterns and different-colored satin are all dyed silk. In the Ming and Qing Dynasties, weaving such a fabric needs a Da Hua Lou draw-loom to cope with those two devices, ground heddle and the lowering harness, so as to weave the figured patterns on satin's two sides.

\section{Silk Patterns of the Fabrics in the Military Banner}

The Russian banner, No. ST21:27, is made up of six fabrics, whose pattern decorations revolve around plants including flowers and fruits, supplemented by mixed treasure, antique, animals and other patterns, so as to make graceful compositions like twines and broken branches.

The pattern of fabric A is composed of broken branches, flowers and fruits, dotted with various treasures (recovery pattern shown in figure 6). There is a line for broken branch of peony interspersed with jade, a line for broken branch of double peaches decorated with ji qing in the middle, a line for broken branch of lotus dotted with pieces of silver and a line for that of double pomegranates interspersed with sheng. Four kinds of miscellaneous treasure patterns are all decorated with ribbons.

The patterns of fabric B is made up of broken branches of peony (recovery pattern shown in figure 7). Two broken branches of peony, naturally shaped, interlace with each other. There are peony and double peaches in one kind of peony broken branch with jade interspersed in one of the peach. And there are a strain of peony and double pomegranates, with qing pattern decorated on one of the pomegranate.

The subjects of flowers and fruits, combined with patterns of various treasures are very popular from Ming dynasty to the early stage of Qing dynasty, because they are full of auspicious notions from traditional Chinese. For example, flowers in full bloom stand for the prosperity, ripe fruits are symbols of the harvest, as well as pomegranate and peach are metaphors for fertility and longevity. From Song and Liao dynasties, patterns of miscellaneous treasures began to appear on the fabric. And also these precious jewels have auspicious meanings, for example, sheng, halberd and qing, because of their pronunciation, are extended into "rising", "good luck", and "celebrating" respectively; horns and coppers, owing to their value, represent richness and honour, and so 
on.

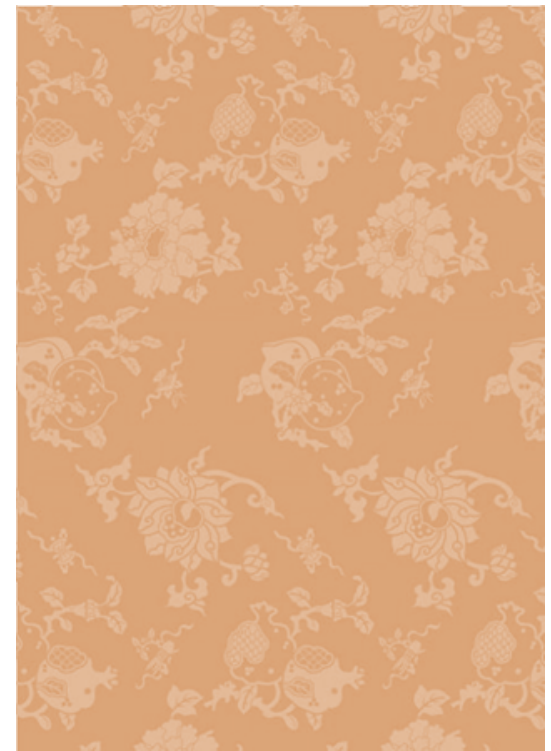

Figure 6. Recovery of fruit and flower branch pattern

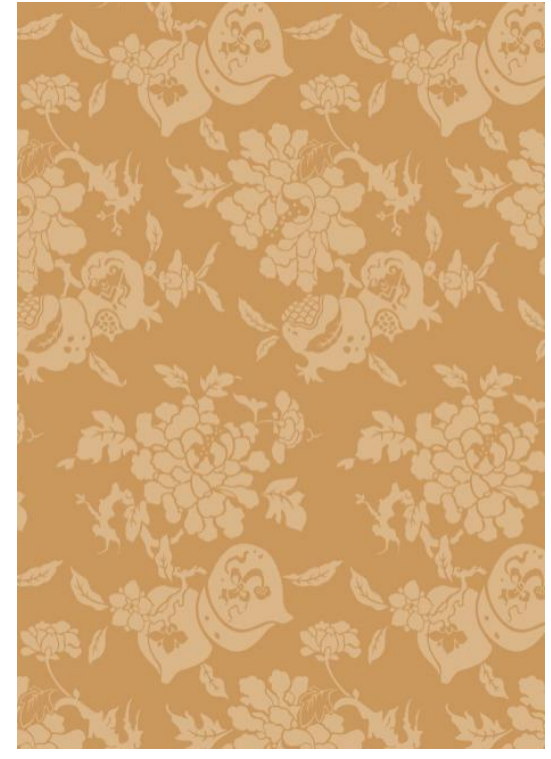

Figure 7. Recovery of peony branch pattern

Fabric $\mathrm{C}$ takes flowers and curio as its patterns (recovery pattern shown in figure 8). It consists of antique and four kinds of broken branches including the branches of orchid flowers, peach flowers, lotus flowers with rolling petals and stretching petals. And broken branches of flowers are dotted with antique patterns, a combination of eight kinds of artifact patterns, covering from qing, gourd and jade, bergamot, fan and qing, guqin, coral bottle and jade slotted ring, bonsai, fangsheng and three peaches, jade cong, jade jue and jade, bookcases and artifacts in the shape of basin, to books, horns and implements in the shape of glass. Antique pattern is said to have originated in Ming dynasty, been popular from late Ming dynasty to Qing dynasty. It was in the reign of Kangxi that porcelain were decorated with many antique patterns. The combination of flowers patterns and antique patterns means nobleness, elegance, wealth and plumpness.
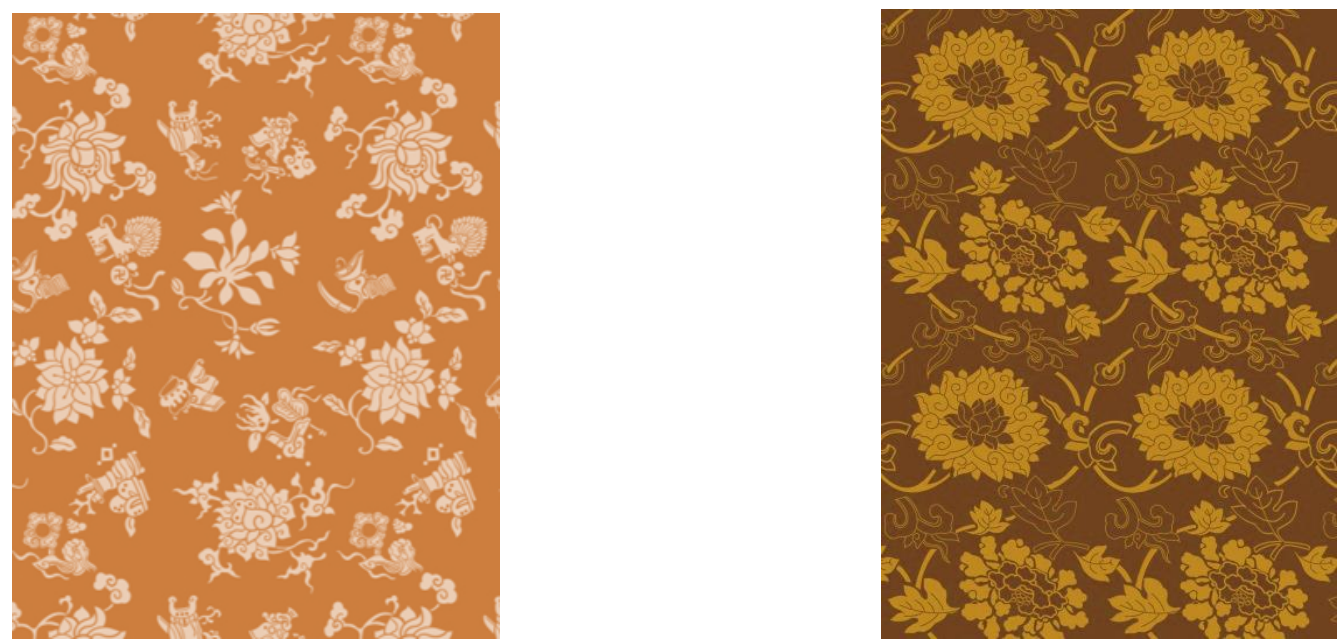

Figure 8. Recovery of flower and curio pattern Figure 9. Recovery of interlocking peony and lotus pattern

Patterns of fabric D consist of interlocking peony and lotus. (recovery pattern shown in figure 9). In the pattern, there is square and continuous skeleton in waving line formed by vines and twines, with peony and lotus in vines of every waving line. As for lotus, the outer petals are scrolling, while the inner petals are lotus-shaped. The heart of it is in the shape of peach, and flame-shaped leaves are decorated with twines around lotus, which is the typical design of lotus in the Ming and Qing dynasties. With respect to peony, its petals stretch naturally, with the blossom in the heart of flower, and its split and stretch into a palmate leaves are interspersed with vines around the peony. The combination of peony and lotus are the implication of wealth and completeness.

Patterns of fabrics E are constituted by grape and squirrel lines (recovery pattern shown in figure 10). Four broken branches of grapes are arranged as a scatter plot, with clusters of grapes on branches and squirrels in four 
different posture climbing in the stems, which is vivid and natural, lively and interesting. Grapes are fruiting well, representing the harvest, wealth and longevity, and squirrel means child, so patterns of grape and squirrel are auspicious symbols of having many sons and grandsons. The above mentioned fabric $\mathrm{E}$ is satin of silk with warp and weft of different colors. What is noticeable is that on military banner, the fabric of the same pattern with fabric $\mathrm{E}$ is also used on the edges that are arranged vertically, but it is reddish brown silk damask with warp and weft of the same color.
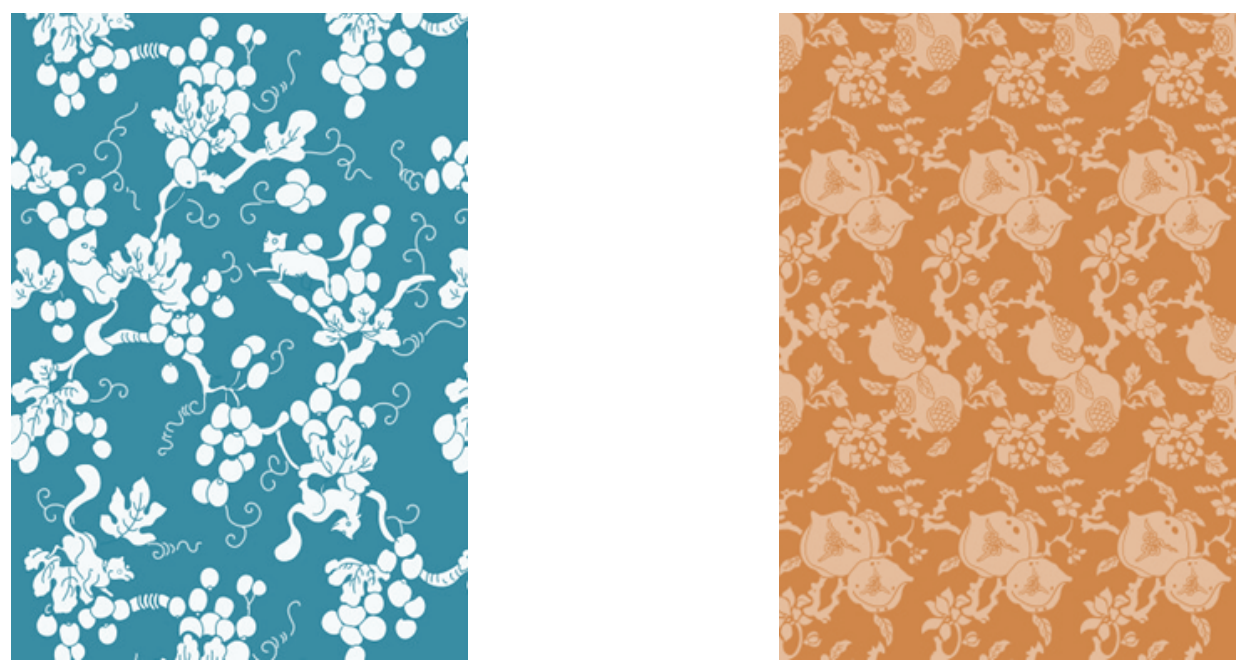

Figure 10. Recovery of squirrel and grape pattern Figure 11. Recovery of pomegranate and peach pattern

Fabric $\mathrm{F}$ takes pomegranate and peach as its patterns. (recovery pattern shown in figure 11). For the pattern, the branches are subtly connected to be "zhi" structure. There are double pomegranates and double peaches on the branches. Two kinds of fruit patterns, staggered in vertical directions, interlace with each other. As for the pair of pomegranate, their fruits are exposed to the outside. With respect to the pair of peach, they are decorated with patterns of ribbons and mixed treasures including the pieces of silver and a single rhino horn respectively. There are magnolia flower and small peach blossom on the main branches of peach, similarly, there are peony and pomegranate flower on the main branches of pomegranate. The combination of peach and pomegranate patterns means fertility and longevity.

Six kinds of fabrics and silk patterns that are used on the Russian military banner, No. ST21:27, are all typically auspicious decorations during the Ming and Qing dynasties in China.

\section{Conclusion}

The Swedish Army Museum collects the Russian military colour No.ST21: 27, which is a trophy of the Swedish army in the Great Northern War in the early 18th century. Its fabric is Chinese silk from the late Ming and early Qing Dynasties.

The silks used in the Russian colour are all satin fabric, which developed to its peak in the Ming Dynasty, and its typical varieties are silk damask and Shan satin with five-end satin. The silk damask with eight-end satin wasn't invented until the Qing Dynasty during the reign of Emperor Kangxi. The silk patterns, like the flowers, fruits, the miscellaneous treasures and the animals, are all about a prevailed aspiration for happiness and longevity in the Ming and Qing Dynasties. After analyzing the weave structures and patterns of the colour, we can draw a conclusion that its fabric is the silk coming from China in Ming and Qing Dynasties. Besides, the time of producing this colour and the war times are consistent, which also confirms us that these fabrics are produced from the late Ming to the early Qing Dynasties in China.

\section{Acknowledgments}

During the study of cultural relics, we received the support from Ms. Lena Engquist Sandstedt of the Swedish Army Museum, and our heartfelt gratitude would be expressed to her once again.

Fund Project: Youth Fund Project of Humanities and Social Sciences Research of Ministry of Education of the People's Republic of China (16YJCZH085)

\section{References}

Archaeological institute of Ningxia, China National Silk Museum, Yanchi Museum. (2010). The Ming tomb at Fengjiquan in Yanchi (pp. 96-98).Beijing: Science Press. 
Bao. Mingxin. (1985). The Monochrome Figured Silk In Ancient China. Journal of East China Institute of Textile Science and Technology, 1, 89-100.

Nockert, M. (2006). Textile Treasures and Simple Fabrics. IN HOC SIGNO VINCES A Presentation of The Swedish State Trophy Collection (p. 189). The National Swedish Museum of Military History.

Qu, Dajun (Qing Dynasty). (1974). Guangdong Xin Yu (p. 427). Volume 15 Products 458 Gauze and Satin. Hong Kong: Zhonghua Book Company Hong Kong branch.

Wu, Zimu. (Song Dynasty). Meng Liang Lu. Volume 18 Products·Silk.

Zhao, F. (2005). A General History of Chinese Silk (p.358, 522). Suzhou: Soochow University Press.

Zhao, F. (2005). A History of Chinese Silk Art (p. 52). Beijing: Cultural Relics Press.

\section{Copyrights}

Copyright for this article is retained by the author(s), with first publication rights granted to the journal.

This is an open-access article distributed under the terms and conditions of the Creative Commons Attribution license (http://creativecommons.org/licenses/by/4.0/). 